\title{
Diffuse Normolipemic Plane Xanthomatosis with Immunoglobulin-Lambda Light-Chain Deposition in a Patient with Multiple Myeloma
}

\author{
Sul Hee Lee, Ji Yeoun Shin, Sang-Hoon Lee, Young Lip Park \\ Department of Dermatology, Soon Chun Hyang University Bucheon Hospital, Bucheon, Korea
}

Dear Editor:

Altman and Winkelmann ${ }^{1}$ first described diffuse normolipemic plane xanthomatosis (DNPX) in 1962. Patients with DNPX usually present with yellowish plaques that characteristically appear on the periorbital region, neck, and flexural folds; plasma lipid levels are normal ${ }^{1,2}$. Relationships with underlying hematological diseases, particularly multiple myeloma and other types of monoclonal gammopathy, have frequently been suggested ${ }^{3,4}$.

A 69-year-old woman presented with a 10-year history of slowly increasing yellow skin lesions on the whole body. She showed symmetrically distributed well-demarcated yellow plaques in both periorbital areas and multiple yel-

\begin{abstract}
low patches and papules in the flexural area, including the axilla and the inguinal region (Fig. 1). The patient did not complain of any systemic symptoms. Laboratory examinations revealed iron deficiency anemia and hypoalbuminemia. Plasma lipid and triglyceride levels were within normal ranges. Urinalysis revealed overt proteinuria and hematuria. Serum electrophoresis showed a monoclonal peak in the gamma region and immunoglobulin G-lambda monoclonal gammopathy. An echocardiogram showed congestive heart failure and a supracardinal lymph-node biopsy revealed amyloid deposition. Renal biopsy demonstrated amyloid light chain-related amyloidosis. Bone marrow biopsy revealed aggregates of plasma cells with lamb-
\end{abstract}
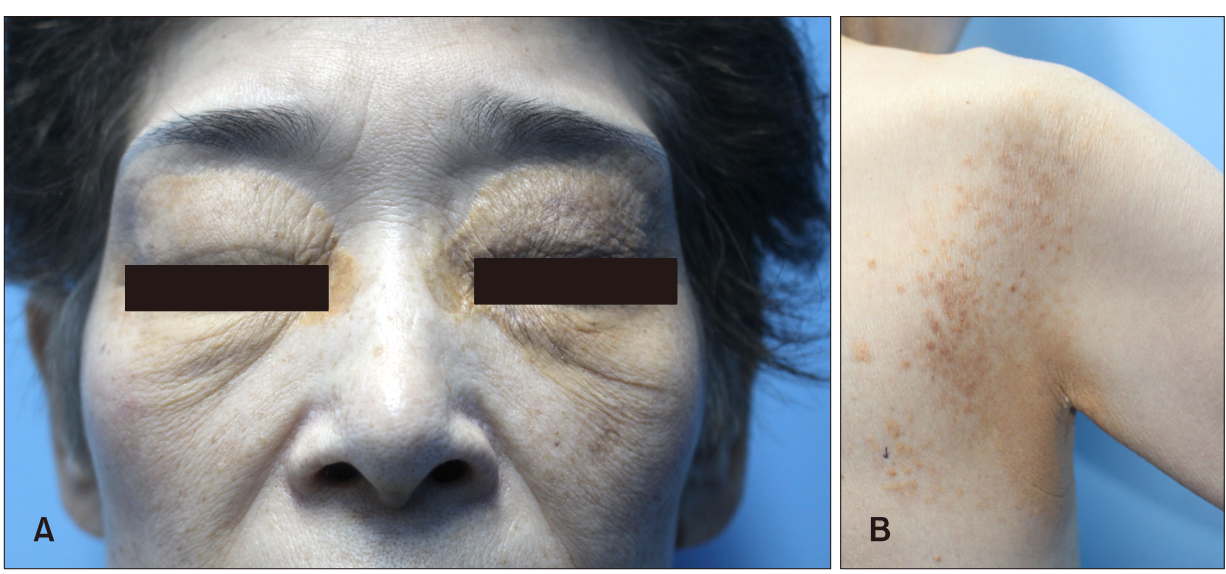

Fig. 1. (A) Symmetrically distributed yellow plaques on both periorbital areas. (B) Yellow patches, papules on the axilla. We received the patient's consent form about publishing all photographic materials.

\footnotetext{
Received October 20, 2017, Revised February 10, 2018, Accepted for publication April 4, 2018
}

Corresponding author: Young Lip Park, Department of Dermatology, Soon Chun Hyang University Bucheon Hospital, 170 Jomaru-ro, Wonmi-gu, Bucheon 14584, Korea. Tel: 82-32-621-5062, Fax: 82-32-327-3550, E-mail: ylpark@schmc.ac.kr ORCID: https://orcid.org/0000-0002-6532-3156

This is an Open Access article distributed under the terms of the Creative Commons Attribution Non-Commercial License (http://creativecommons.org/ licenses/by-nc/4.0) which permits unrestricted non-commercial use, distribution, and reproduction in any medium, provided the original work is properly cited.

Copyright $\odot$ The Korean Dermatological Association and The Korean Society for Investigative Dermatology 

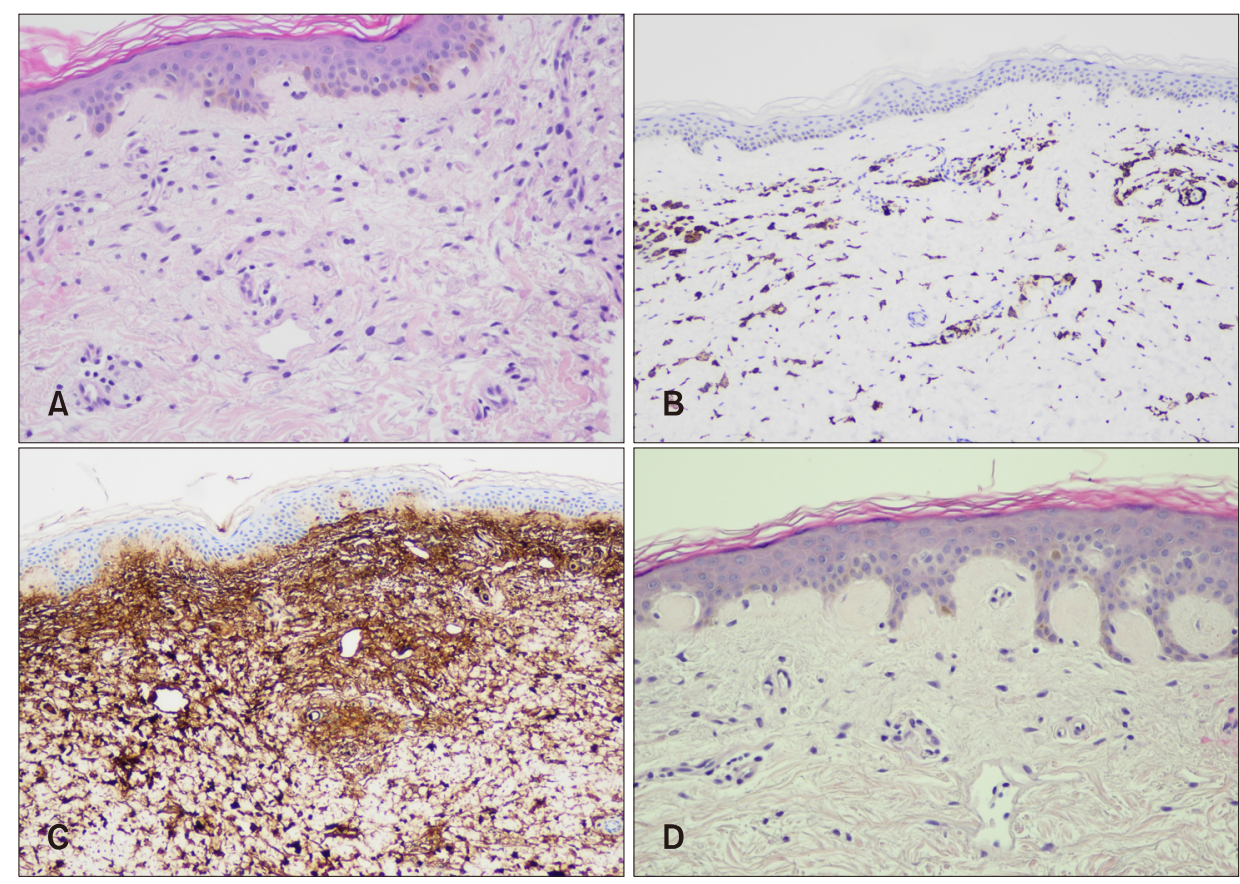

Fig. 2. (A) Scattered foamy histiocytes are observed in the upper and mid dermis, with an admixture of histiocytes and lymphocytes $(\mathrm{H} \& \mathrm{E}, \times 200)$. (B) Immunohistochemical staining was diffusely positive for CD68 (CD68, × 100). (C) Dense staining throughout the entire dermis for the immunoglobulin-lambda light chain is noted (lambda chain, $\times 100$ ). (D) Globular deposits of homogenous, faintly eosinophilic materials in the papillary dermis $(H \& E, \times 200)$. da monoclonality. Based on these findings, the patient was diagnosed with multiple myeloma. A skin biopsy from her axilla showed scattered foamy histiocytes in the upper and mid dermis, with an admixture of histiocytes and lymphocytes (Fig. 2A). Immunohistochemical staining was diffusely positive for CD68 (Fig. 2B). Dense staining throughout the entire dermis for the immunoglobulinlambda light chain was also observed (Fig. 2C). These findings were consistent with DNPX. The papillary dermis contained globular deposits of homogenous, faintly eosinophilic materials (Fig. 2D). However, they showed no definite affinity to congo red.

The pathogenesis of DPNX remains unclear. The previously suggested pathogenesis of DNPX is that monoclonal immunoglobulins bind to circulating low-density lipoproteins in plasma and form complexes around vessels in the skin, where they are phagocytosed by macrophages, which finally appear as foam cells ${ }^{3,4}$. Several cases of DNPX associated with monoclonal gammopathy have been reported to date $e^{3-5}$, but this report is the first to describe dense lambda immunoglobulin deposition with infiltration of histiocytes in the entire dermis, as revealed by skin biopsy. Furthermore, we cautiously suggest the coexistence of cutaneous amyloidosis, which is another unique finding of this report, based on the observation of globular deposits of eosinophilic materials in the papillary dermis on histological examination. Cutaneous amyloid deposition may exist in this patient, considering that it is one of the symptoms of multiple myeloma, and the patient also had accompanying cardiac and renal amyloidosis. Although the globular deposits show no definite affinity to congo red, inadequate tissue quantity and staining might have caused a false negative result or decreased sensitivity.

Although not all xanthomas are associated with systemic diseases, DNPX may appear as the first symptom of underlying malignant hematological or lymphoproliferative diseases $^{5}$. Therefore, in patients with DNPX, skin biopsy and hematological evaluation should be performed, and close follow-up with periodic laboratory testing is recommended.

\section{ACKNOWLEDGMENT}

This work was supported by the Soonchunhyang University Research Fund.

\section{CONFLICTS OF INTEREST}

The authors have nothing to disclose.

\section{ORCID}

Sul Hee Lee, https://orcid.org/0000-0002-2990-9774 Ji Yeoun Shin, https://orcid.org/0000-0002-4859-4069 Sang-Hoon Lee, https://orcid.org/0000-0002-7146-3702 Young Lip Park, https://orcid.org/0000-0002-6532-3156

\section{REFERENCES}

1. Altman J, Winkelmann RK. Diffuse normolipemic plane xanthoma. Generalized xanthelasma. Arch Dermatol 1962; 
Brief Report

85:633-640.

2. Lynch PJ, Winkelmann RK. Generalized plane xanthoma and systemic disease. Arch Dermatol 1966;93:639-646.

3. Rosmaninho A, Fernandes I, Guimas A, Amorim I, Selores M. Diffuse plane xanthomatosis associated with monoclonal gammopathy. An Bras Dermatol 2011;86(4 Suppl 1): S50-S52.
4. Taylor JS, Lewis LA, Battle JD Jr, Butkus A, Robertson AL, Deodhar $S$, et al. Plane xanthoma and multiple myeloma with lipoprotein--paraprotein complexing. Arch Dermatol 1978; 114:425-431.

5. Loo DS, Kang S. Diffuse normolipidemic plane xanthomas with monoclonal gammopathy presenting as urticarial plaques. J Am Acad Dermatol 1996;35:829-832.

\title{
Docetaxel-Aggravated Psoriasis
}

\author{
Seungkeol Yang, Bo Ri Kim, Chong Won Choi, Sang Woong Youn \\ Department of Dermatology, Seoul National University College of Medicine, Seoul National University Bundang Hospital, Seongnam, Korea
}

\section{Dear Editor:}

A 78-year-old man with a 50-year history of psoriasis presented with generalized erythematous scaly plaques involving the scalp and face (Fig. 1). Over 5 years, the psoriasis had been confined to the hands and feet and controlled using topical agents alone. Three days prior to emergence of the rash, he reported being administered the first dose of docetaxel $90 \mathrm{mg}$ as treatment for prostate cancer. No aggravation of the psoriasis had been observed throughout past 4 years of treatment with antiandrogens and radiotherapy.

At the present visit, the psoriasis area severity index score was 10.4 , and the percentage of body surface area involved was $20 \%$. Given his medical history and clinical features, we concluded that the preexisting psoriasis had exacerbated due to the newly introduced docetaxel treatment. The patient was treated with acitretin at a dose of $20 \mathrm{mg}$ daily and topical calcipotriol/betamethasone dipro-
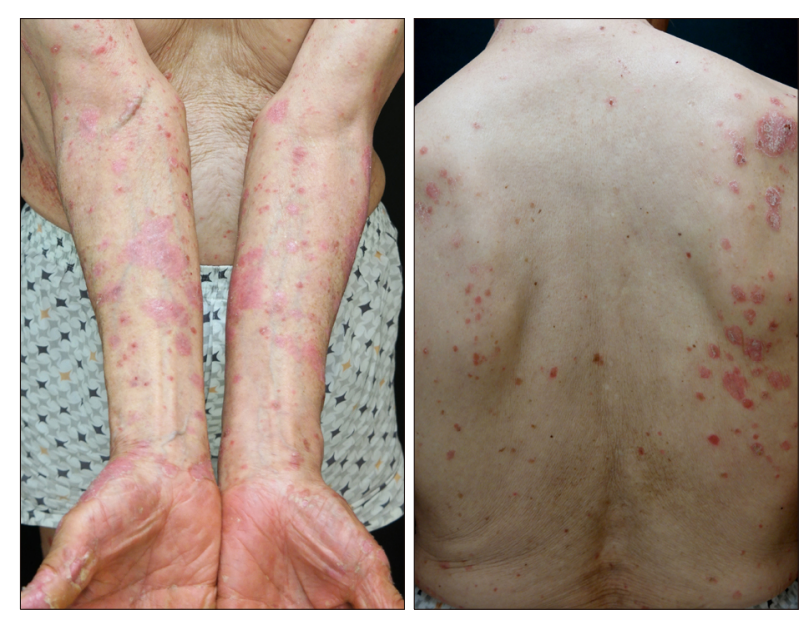

Fig. 1. Scaly erythematous plaques that appeared 3 days after the administration of docetaxel. We received the patient's consent form about publishing all photographic materials.

Received January 22, 2018, Revised March 28, 2018, Accepted for publication April 4, 2018

Corresponding author: Sang Woong Youn, Department of Dermatology, Seoul National University College of Medicine, Seoul National University Bundang Hospital, 82 Gumi-ro 173beon-gil, Bundang-gu, Seongnam 13620, Korea. Tel: 82-31-787-7319, Fax: 82-31-787-4058, E-mail: swyoun@snu.ac.kr ORCID: https://orcid.org/0000-0002-5602-3530

This is an Open Access article distributed under the terms of the Creative Commons Attribution Non-Commercial License (http://creativecommons.org/ licenses/by-nc/4.0) which permits unrestricted non-commercial use, distribution, and reproduction in any medium, provided the original work is properly cited.

Copyright (C) The Korean Dermatological Association and The Korean Society for Investigative Dermatology 